Article

\title{
Should We Trust in Values? Explaining Public Support for Pro-Environmental Taxes
}

\section{Niklas Harring ${ }^{1, *}$ and Sverker C. Jagers ${ }^{2}$}

1 Department of Political Science, University of Gothenburg, Sprängkullsgatan 19, P.O. Box 711, SE 40530 Gothenburg, Sweden

2 Political Science Unit, Luleå University of Technology \& Department of Political Science, University of Gothenburg, Sprängkullsgatan 19, P.O. Box 711, SE 40530 Gothenburg, Sweden; E-Mail: sverker.jagers@pol.gu.se

* Author to whom correspondence should be addressed; E-Mail: niklas.harring@pol.gu.se; Tel.: +46-31-786-1223.

Received: 27 November 2012; in revised form: 24 December 2012 / Accepted: 1 January 2013 / Published: 16 January 2013

\begin{abstract}
In this paper we are concerned with what explains public acceptance and support of environmental taxes. We examine findings in environmental psychology emphasizing that people's (environmental) value-orientation is the dominant driver determining individuals' support for pro-environmental policy instruments. We introduce a complementary model, mainly drawing upon findings in political science, suggesting that people's support for policy instruments is dependent on their level of political trust and their trust in other citizens. More specifically, we analyze whether political trust and interpersonal trust affect individuals' support for an increased carbon dioxide tax in Sweden, while checking their value orientation, self-interest, and various socio-economic values. We make use of survey data obtained from a mail questionnaire sent out to a random sample of 3,000 individuals in 2009. We find that apart from people's values, beliefs, and norms, both political trust and interpersonal trust have significant effects on people's attitudes toward an increased tax on carbon dioxide.
\end{abstract}

Keywords: sustainable development; environment; environmental politics; values; trust; policy instruments 


\section{Introduction}

Environmental problems can be seen as distinct examples of collective action problems [1], or so-called social dilemmas [2]. This means that, for individual actors, the short-term benefit of (ab)using the environment (i.e., a "defecting behavior") tends to exceed the longer-term collective losses and, thus, counteracts cooperative behavior. A number of environmental problems exceed the capacities of individuals and/or local collective initiatives, necessitating the intervention of larger political entities to provide governance at the local, regional, national, and international scales [3]. However, when following up on this topic-asking what would be an appropriate political route towards a well-functioning (i.e., cost-efficient, legitimate, and effective outcome) [4] protection of the environment - the scholarly opinions diverge. For example, among political theorists, a classic watershed is one between those asserting that collective action problems are best overcome via topdown politics, e.g., initiated by the "Green State" (e.g., [5-9]), and those claiming that wellfunctioning environmental politics is better founded in discursive or deliberative democratic ideals (e.g., $[10-12])$.

An adjacent debate concerns the most appropriate policy or steering instruments aimed at shaping individuals' or other actors' pro-environmental behavior. Historically, environmental protection has primarily been based on state-based environmental protection, such as legislation and prohibition. However, while environmental degradation today is increasingly perceived as being based on individual citizen or consumer choices, fewer argue that coercive and rigid policies will solve the problem [13-17]. Some advocate for measures primarily aimed at "guiding" citizens toward pro-environmental behavior, e.g., via information or education $[18,19]$.

In between those advocating either coercive prohibition and guiding principles, there is a large body of scholars - not least economists - asserting that many environmental collective action problems can best be resolved through the use of market-based policy instruments, e.g., because they are cost-efficient and/or because they tend to leave a certain amount of freedom of choice (e.g., [20-24]). The latter group of policy instruments is in focus in this paper.

However, it is one thing to claim and demonstrate that market-based instruments are (economically) efficient and quite another to eventually gain public support for them. This has motivated scholars to investigate why some people tend to accept such environmental policy instruments while others do not. Hitherto, such studies have largely been performed by environmental psychologists, who conclude that environmental behavior-in which acceptance of environmental policy instruments is typically included $[25,26]$ — is determined by individuals' value-orientation, environmental beliefs, norms and policy-specific attitudes (e.g., [27-30]). As indicated, much of this research is rather issue-specific, i.e., many of the values, norms, and beliefs included are associated with the environment. We argue that a too narrow focus on such factors runs the risk of excluding other factors potentially affecting policy acceptance.

For example, while market-based policy instruments (especially taxes) are gaining ground across the world [23], they have potential drawbacks that are not necessarily associated with environmental effectiveness and economical efficiency as such. Instead they are related to various political and institutional factors that we hypothesize may affect their acceptability. For example, due to the underlying social dilemmas, there is constantly a risk of free-riding or market failures unless there is a 
rigorous enough control system attached to them. Market-based instruments are also often criticized for being unfair, as they tend to have regressive effects on income and thus hit unevenly in societies with large income variation. We suggest that the less trustworthy politicians and/or implementing authorities are, the less likely it is that marked-based instruments will gain public support. This is either because the motives of the instruments can be questioned, or because it is unclear what happens with the revenues once they have been collected (e.g., [31-33]).

Thus, the aim of the paper is to analyze whether political and interpersonal trust add significantly to the value-based explanations of support for environmental taxes. We do this by using survey data obtained from a mail questionnaire sent out in 2009 to a random sample of 3,000 individuals in Sweden.

The remaining of the paper is organized as follows. In section 2, we review previous research on factors affecting individuals' support for pro-environmental policy instruments. We also specify a model, which we use to derive hypotheses. In section 3, we introduce our data, discuss methodological issues, and account for how our dependent and independent variables are operationalized. In the subsequent section 4, we present our results. We conclude the paper by discussing our major findings, namely that political trust, interpersonal trust, and personal values turn out to have independent and significant effects on people's attitudes toward an increased tax on carbon dioxide.

\subsection{Theorizing Acceptance of Pro-environmental Policy Instruments}

To date, the theory and practice of environmental politics and policy have primarily been concerned with devising alternative ways of societal organization, and with the development of new innovative institutions for steering contemporary societies in a more sustainable direction. Gradually, however, scholars engaged in finding new approaches to dealing with social dilemmas in the form of environmental problems are directing their focus toward the individual, both as a citizen and as a consumer [34-36]. In a sense, we can say that there has been a re-interpretation of the responsibility for both causes of and solutions to environmental problems, placing the activities of the individual center stage [37-40]. Acknowledging that the aggregated day-to-day behavior of single individuals is one of the major sources of contemporary environmental problems, more environmentally responsible personal lifestyle decisions are seen as a key approach to reach sustainability.

Several paths toward behavioral change are possible. For example, some scholars argue (or hope) that people adopt more pro-environmental behavior due to fundamental changes in their personal values and beliefs [18]. However, as a person's belief system is commonly understood as being relatively enduring and stable over time $[41,42]$, reliance on individual value-changes presents an uncertain and long-term route to increased pro-environmental behavior. Although important, values are, however, not the sole factor determining how a person chooses to behave. Previous research clearly demonstrates that the effect of values on behavior is mediated not only by a range of factors such as environmental concern, ideology, perceptions, and sense of fairness, but also by social norms and personal norms $[26,30,43-45]$.

These latter findings imply that behavioral change can be politically induced, as people are expected to adjust their behavior in response to changes in their surrounding structure of incentives. In this endeavor, the list of potentially efficient policy tools is long, ranging from informational to market-based and legal instruments, as well as from pull-strategies presenting a sustainable alternative 
as more advantageous for the individual to push-strategies exacerbating the negative impact of practicing unsustainable activities. In this paper, we have a special focus on environmental taxes, which is a type of policy instrument currently winning ground in both developed and developing countries $[22,23,46]$. With the above terminology, an environmental tax should be seen as an example of a market-based push-strategy aimed at increasing the price of unsustainable behavior (by serving to internalize externalities). Thus, when the price is increasing, the incentive to change behavior is expected to increase too.

A common argument for employing taxes is that they are often comparatively economically efficient [20,21,23] — clearly an important lodestar for politicians and policy-makers. However, it is questionable whether this criterion alone is good enough for adopting them. When designing policy tools, decision-makers constantly face the challenge of carefully striking a balance between efficiency and legitimacy, as the level and direction of public policy support can be expected to have a major impact on subsequent policy performance (e.g., [47]). Furthermore, unless the measure displays sufficient potentially broad public support, the suggested policy instrument will likely not be advocated in the political sphere, and thus will not be implemented [48-52]. As we see it, it is therefore necessary for a society and its policy-makers to understand the conditions under which environmental taxes are considered legitimate among the public. In the next section, we elaborate a number of factors arguably affecting individuals' acceptance of environmental policy instruments in general and acceptance of environmental taxes in particular.

\subsubsection{Values, Beliefs, and Norms (VBN) as a Determinant of Policy Acceptance}

Within environmental psychology, a great deal of research conducted over the past decades is founded on the assumption that pro-environmental behavior, including pro-environmental policy acceptance, has its roots in personal values, i.e., general conceptions of the desirable, that guide the individual's selection of actions and evaluation of people and events [41]. Combined with theories of norm activation (e.g., [53]), research on the psychological determinants of everyday pro-environmental behavior has resulted in the establishment of hierarchical models, where the effect of general values on behavior is mediated by beliefs and worldviews providing the individual with an understanding of the empirical nature of the domain, including his/her own place in it. The value-belief-norm (VBN) theory of environmental support $[25,26]$ assumes that many behavioral activities are the result of a causal chain that starts with personal value priorities, which lead to beliefs (i.e., general environmental beliefs; awareness of environmental consequences; ascription of personal responsibility for these consequences) and finally the formation of personal norms of behavior. Throughout the literature, there is a range of evidence in support of the VBN theory's validity as it has been shown to account for variance in many forms of environmentally related behavior (e.g. [26,30,54-57]).

\subsubsection{Broadening the Scope-Political Trust as a Determinant of Policy Acceptance}

Broadly speaking, if the environmental-psychological findings really capture most of what is needed to explain pro-environmental behavior and policy acceptance, all it takes to overcome environmental collective action problems is a strong enough pro-environmental value orientation. Any such conclusions can, however, be questioned as it has been demonstrated that there are truly "green" 
individuals who nevertheless refuse to accept many pro-environmental policy instruments. In addition, there are also typically "grey" individuals who all the same demonstrate both strong pro-environmental behavior and willingness to accept pro-environmental policy instruments $[32,58,59]$. Thus, the fact that I may have strong green sympathies and concerns is no guarantee that I am willing to accept political initiatives aimed at improving the environment. This willingness is also based on, e.g., attitudes to authority and political steering in general and to the particular authorities implementing the policy instrument in particular [60].

By bringing in political or institutional settings, such as the rules of the game, into the analysis, we open the floor for change because, although it is often complicated to achieve political or institutional change, it is probably even more difficult to change personal values [41,42]. Thus, instead of green-washing grey people - a project that will probably generate results only in the long term - an alternative route may be to change the rules of the game in such a way that pro-environmental policy acceptance is induced among both green and grey people.

In a survey study of the Swedish population's attitudes to climate change-related policy instruments, Hammar and Jagers [60] discovered several factors explaining individuals' pro-environmental policy support, e.g., self-interest, economic status, and sense of justice. Of more concern here, however, is that they—substantiated by Torgler [61-63], Tyler [64], and Sandmo [65] and theoretically argued by Uslaner [66] - find that people's propensity to support policy instruments is also affected by their political trust. They reason that the more people trust their politicians (measured as "politicians," "the parliament," and "the government"), the more likely they are to accept an increased tax level. This result is made comprehensible through two lines of reasoning. First, unless people trust in the competence of their popularly elected politicians, i.e., that the politicians know what is required to combat climate change and that a $\mathrm{CO}_{2}$ tax is the road towards success, they will not be apt to accept an increased tax. Second, unless people trust that the political institutions can and will deal with the revenues of the taxes in a righteous, effective, and proper way, they will be less willing to also accept or support such a tax. We endorse such reasoning and take this as an assumption in our study. Thus, we assume that political or institutional trust has an effect on policy acceptance. Furthermore, since such trust is reasonably disengaged from the issue at stake, i.e., the environment, the effect of political trust should be independent of the VBN chain.

\subsubsection{Inter-personal Trust as a Determinant of Policy Acceptance}

Our next factor is closely linked to the core dilemma largely constituting "environmental problems," namely individual actors' propensity to neglect cooperation in favor of adopting selfish behavior. This dilemma has repeatedly been demonstrated, discussed, and analyzed in everything from real world examples to experimental studies. One important factor that determines whether the individual chooses to cooperate or not, is reciprocity. Most people may have a general disposition to cooperate, but this propensity is partly conditioned by their trust that the other citizens or involved actors will cooperate too [2,67-70]. A similar (but not identical) line of reasoning can be applied to our specific case of environmental taxes: Reasonably, individuals' attitudes to environmental taxes are shaped by their perception as to whether they trust in the cooperation of others. 
In our case of environmental taxes, this broad logic is applicable in two ways. First, people will support environmental taxes while doubting the likelihood that others will do likewise, i.e., to act in an environmentally friendly way of their own accord. One motivation for such behavior is that positive action is necessary to offset the negative effect of those acting selfishly Second, the policy tool in itself is based on cooperation. Thus, if people instead perceive that their fellow citizens are dishonest and they doubt that people will comply with the environmental tax, they will be less inclined to support it. We find certain support for this proposition in a study by Hammar, Jagers, and Nordblom [71], where it was found that people's propensity to accept increased taxes depends on the degree to which it is possible to escape them, indicating people's suspicion that others will defect. The more unavoidable taxes are (difficult to evade), the more willing people are to accept increases of them. Furthermore, it was found that the weaker people's trust in their co-citizens, the stronger they perceive that taxes are systematically evaded (which also affects their willingness to accept taxation increases). Several other studies also conclude that perceptions of tax evasion and tax compliance are correlated with tax morale $[61,62,65,72]$. Transferring these findings into our context, we ask whether low interpersonal trust generates an aversion to environmental taxes. Based upon what has been established in this section, the following hypotheses can now be derived.

$\mathrm{H} 1_{\mathrm{A}}$. In accordance with the VBN model, people with a stronger personal norm for pro-environmental behavior are more likely to accept increases of pro-environmental taxes.

$\mathrm{H} 1_{\mathrm{B}}$. In accordance with the VBN model, personal norms largely mediate the effects of other antecedent factors such as personal values, worldview, awareness of consequences, and ascription of responsibility.

H2. The more political trust people have, the more likely they are to accept increases of pro-environmental taxes.

H3. The more general trust people have in their fellow citizens, the more likely they are to accept increases of pro-environmental taxes.

H4. The less trust they have in their fellow citizens acting environmentally friendly, the more likely citizens are to accept increases of pro-environmental taxes.

\subsection{Data and Measurement}

In order to test our hypotheses, we use survey data based on a random sample from the Swedish population register. To collect the data, a self-administered mail-questionnaire was sent to the sample consisting of 3,000 individuals, 18 to 80 years old. The fieldwork was conducted during approximately a two-month period from the end of April to the end of June in 2009. The overall response rate was $36 \%$, which yielded a total of 1,057 completed questionnaires. Because of the rather moderate response rate, systematic comparisons were conducted with a similar annual postal survey carried out by the SOM institute at the University of Gothenburg, which has an overall high response rate (close to $60 \%$ in 2008 ) and a reputation for high quality fieldwork and representative samples. These comparisons show that the response rate has not severely affected the representativeness of our respondents. The general impression is that they correspond substantially in terms of socio-economic, political, and attitudinal variables. Our conclusion from these comparisons is that the dataset we use is fairly accurate and 
representative of the Swedish public despite the moderate response rate. A full report of these comparisons is found in Appendix 1.

The dependent variable is operationalized through a question on people's attitudes to "an increased $\mathrm{CO}_{2}$ tax on gasoline" which is included in a battery of questions on people's attitudes to different policies or measures to limit Swedish $\mathrm{CO}_{2}$ emissions. The respondents could choose whether they consider this policy "a very bad suggestion", "a rather bad suggestion", "a neither good nor bad suggestion", "a rather good suggestion" or "a very good suggestion." We have translated these alternatives into a $1-5$ scale where 1 indicates that it is "a very bad suggestion" and 5 that it is "a very good suggestion". We have formulated our hypotheses in a rather general way regarding environmental taxes, and the dependent variable is operationalized through a question concerning a specific $\mathrm{CO}_{2}$ tax increase. Given the extent of contemporary public debate over this specific tax in Sweden, it is considered that the responses to the gasoline tax are representative of pro-environmental taxes in general.

When it comes to measuring the components of the VBN model of pro-environmental behavior, we follow the standard procedure in environmental psychology. In terms of personal values, we measure egoistic (self-enhancement) and altruistic (self-transcendence) values in the same way as for example Steg and colleagues [30] used a short version of Schwartz's [73] universal values scale. To measure peoples' worldview, we use a shortened version of the revised edition of the New Environmental Paradigm (NEP2), developed by Dunlap and colleagues [74]. We thus only use 10 items instead of the full 15 item version, but have balanced the items so that each of the five sub-components are equally represented [75]. The last three components in the VBN chainawareness of consequences [76], ascription of responsibility [77], and personal norm [78]—were measured with at least three indicators each, all of them achieving acceptable reliability (see Table 1).

As has already been argued above, we hypothesize that people's perceptions of whether or not others are cooperating affect their acceptance of environmental taxes in two different ways: (1) If people perceive that others do not behave environmentally friendly, they support environmental taxes since people then need to be pushed or encouraged to act environmentally friendly, through for example environmental taxes. In order to capture this, we build an index out of six questions on whether they perceive that other people are acting environmentally friendly [79]. (2) Taxes as a policy tool depend on cooperation in the sense that people actually pay their taxes. This cooperation is based on interpersonal trust $[65,80]$. To measure interpersonal trust, we use the question, "Generally, to what extent do you feel that people can be trusted?" with a $0-10$ response scale. As a $\mathrm{CO}_{2}$ tax is harder to evade than for example income tax, this can be considered as a tough test for the hypothesis that trust matters for tax acceptance [71].

In order to measure political trust, we use an index based on four questions regarding people's trust in "government", "parliament", "Swedish authorities", and "politicians", where people are asked to what extent they trust each of these institutions on a 1-5 scale [81].

We check for ideology, income, residence, and how often people travel by car to work/school. Ideology is based on a question where people place themselves on a scale from left to right (0-10) [82]. The responses are separated into three different categories: left (0-4), center (5), and right (6-10). Income is coded into three different categories: low-income earners (15,000 SEK/month or less), middle-income earners (15,001-25,000 SEK/month), and high-income earners $(25,001 \mathrm{SEK} / \mathrm{month}$ or 
more) [83]. To capture self-interest, we use residence [84] and questions about how often people travel by car to work/school [85]. People who live in the countryside generally have limited access to public transportation and are more dependent on cars, and people who state that they often go by car are more affected by an increased $\mathrm{CO}_{2}$ tax.

Table 1. Descriptive statistics.

\begin{tabular}{llccc}
\hline Variable & Construct & Min & Max & Mean \\
\hline Increased $\mathrm{CO}_{2}$ tax on gasonline & 1 item & 1 & 5 & 2.71 \\
Self-enhancement values & 5 items (alpha 0.70) & -0.20 & 7 & 2.71 \\
Self-transcendence values & 4 items (alpha 0.77) & -0.25 & 7 & 4.94 \\
New environmental paradigm & 10 items (alpha 0.66) & 1.9 & 5 & 3.64 \\
Awareness of consequences & 5 items (alpha 0.74) & 1 & 7 & 5.21 \\
Ascription of responsibility & 5 items (alpha 0.69) & 1 & 7 & 5.26 \\
Pro-environmental personal norm & 4 items (alpha 0.72) & 1 & 7 & 5.3 \\
Political trust & 4 items (alpha 0.83) & 1 & 5 & 2.88 \\
Interpersonal trust & 1 item & 0 & 10 & 6.2 \\
Trust in fellow citizens acting & & & & \\
environmentally friendly & 6 items (alpha 0.67) & & & 3.71 \\
Car usage & Often (5-7 days/week), & & \\
& Seldom (<3 times/month), & & & \\
Medium use (from $>3$ times/ & & & \\
Income & month to $<5$ days/week) & & & \\
& Left, Center, Right & & & \\
\hline
\end{tabular}

\section{Results and Discussion}

In Table 2, we account for the results in our regression analyses. All in all, we study seven different models in order to test our hypotheses regarding what explains public support for an increased $\mathrm{CO}_{2}$ tax. In the first five models, we are concerned with the hierarchical VBN chain, and as it is hierarchical, we test it by adding factors in the models. Thus, in model 1, we only investigate the importance of values, i.e., the effect of people being primarily egoistic or altruistic in their value orientation. In model 2, we add environmental attitudes by including the NEP index (New Environmental Paradigm). In the third model, we include people's awareness of consequences. Model 4 also contains people's ascription of responsibility and in model 5 the VBN chain is complete as we there also include pro-environmental personal norms. In model 6, we include three aspects of trust: political trust, interpersonal trust, and people's perceptions of other people's environmental behavior (do they trust that others contribute as they should?). In the seventh and final model, we also include our control variables ideology, income, residence, and car usage. The table shows unstandardized coefficients, except for model 7 for which we also declare the standardized coefficients. 
Table 2. Attitudes to an increased $\mathrm{CO}_{2}$ tax on gasoline. OLS regression analysis.

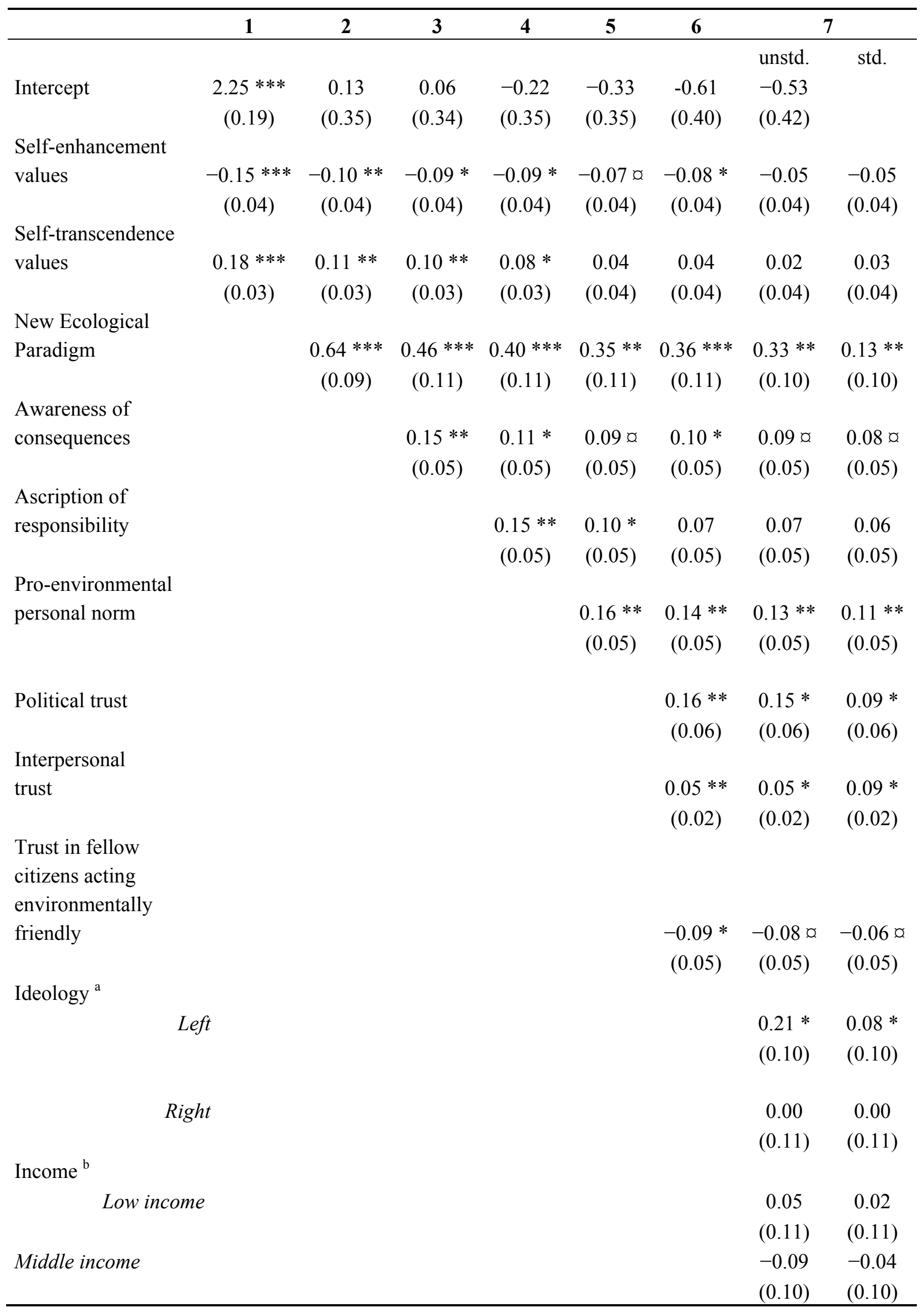


Table 2. Cont.

\begin{tabular}{|c|c|c|c|c|c|c|c|c|}
\hline \multicolumn{9}{|l|}{ Car usage $^{c}$} \\
\hline 3 times a month) & & & & & & & $\begin{array}{c}0.18 \\
(0.12)\end{array}$ & $\begin{array}{c}0.07 \\
(0.12)\end{array}$ \\
\hline \multicolumn{9}{|l|}{ Often (5-7 days } \\
\hline a week) & & & & & & & $\begin{array}{c}-0.23 \mathrm{\alpha} \\
(0.13)\end{array}$ & $\begin{array}{c}-0.09 \propto \\
(0.13)\end{array}$ \\
\hline \multicolumn{9}{|l|}{ Residence $^{\mathrm{d}}$} \\
\hline City & & & & & & & $\begin{array}{c}0.32 * * * \\
(0.09)\end{array}$ & $\begin{array}{c}0.11 * * * \\
(0.09)\end{array}$ \\
\hline Countryside & & & & & & & $\begin{array}{c}-0.22 \propto \\
(0.12)\end{array}$ & $\begin{array}{c}-0.06 \times \\
(0.12)\end{array}$ \\
\hline $\mathrm{N}$ & 792 & 792 & 792 & 792 & 792 & 792 & 792 & 792 \\
\hline Adj. R-sq & 0.045 & 0.104 & 0.115 & 0.127 & 0.138 & 0.163 & 0.222 & 0.222 \\
\hline
\end{tabular}

Comment: $\propto p<0.10,{ }^{*} p<0.05,{ }^{* *} p<0.01,{ }^{* * *} p<0.001$. a: reference category-center; b: reference category - high income earners; c: reference category-more than 3 times a month but less than 5 days a week; d: reference category; town. Unstandardized coefficients in all models, except model 7, which shows both unstandardized and standardized coefficients.

Since the VBN chain is hierarchical, we should expect factors positioned earlier in the causal chain to decrease in impact and significance the more components of the model we include. For example, in the first models, values should have a significant effect on $\mathrm{CO}_{2}$ tax support, but these effects should weaken and gradually disappear the more components of the VBN chain we add to our models. This is a pattern that we find in the first five models. Self-enhancement values do have significant (negative) effects on $\mathrm{CO}_{2}$ tax support $\left(-0.15^{* * *}\right)$, and so do self-transcendence values, but in the opposite direction $\left(0.18^{* * *}\right)$. As we include the NEP index, the effects of values immediately become weaker $\left(-0.10^{* *} / .11^{* *}\right)$. When the whole VBN chain is completed in model 5 , we see that the effects of values (and the other previous VBN factors) are even weaker and only occasionally significant. As we see by comparing R-square values further down in the table, the explanatory power of the VBN model systematically increases the more components we add to the model (from 0.045 in model 1 to 0.138 in model 5).

What then happens when we add the various trust variables to our models? As we see in model 6, independent of the VBN chain, political trust has a positive effect $\left(0.16^{* *}\right)$. Thus, the more political trust you have, the more likely you are to be supportive of an increase in the Swedish $\mathrm{CO}_{2}$ tax. The same is the case with interpersonal trust $\left(0.05^{* *}\right)$. The more you trust other people in general, the more likely you are to support a tax increase. In regard to trust in people's environmental behavior, the effect is negative $(-0.09 \mathrm{a})$, as expected. Thus, the more you trust that others are adopting a pro-environmental behavior, the less supportive you are of a tax increase. Important to note is that we find these effects in a model that tests all of the hypotheses simultaneously. Thus, one effect does not outdo the other [86]. However, in model 7, when our control variables are included, the effect of trust that others are 
adopting a pro-environmental behavior, is less strong and only significant at the $90 \%$ level. Furthermore the effect is not significant if the other "trust"-variables are excluded from the model (not shown). On the other hand, both political trust $\left(0.15^{*}\right)$ and interpersonal trust $\left(0.05^{*}\right)$ still have positive effects on $\mathrm{CO}_{2}$ tax support and remain significant, even under control for other important variables.

Considering the control variables, we see that left-oriented ideology has a positive and significant effect $\left(0.21^{*}\right)$. Among left-oriented people, there is generally a larger degree of tax support and furthermore, compared to right-wing respondents, we typically find more environmentally concerned people within this group (e.g., [60]). What about income? Here we have compared two groups-lowincome and middle-income people - with the respondents clustered as high-income earners as the reference category. We then find the following: the effect of low-income is positive (0.05) while the effect of middle-income is negative $(-0.09)$, as expected. However, the effects are not statistically significant. If we look at self-interest, the results are as anticipated. People who live in the countryside are often more dependent on cars and are also less likely to support a $\mathrm{CO}_{2}$ tax increase $(-0.22 \mathrm{a})$, while people living in cities are more positive to such a tax $(0.32 * * *)$. Furthermore, the self-interest hypothesis gains even more support in that people who use a car to get to work are less likely to support a $\mathrm{CO}_{2}$ tax increase $(-0.23 \times)$ compared to people who use a car less often.

Finally, what is the influence on these relationships when we include our trust variables? If we examine the adjusted R-square values at the bottom of the table, we see that the figures are changing when we complement the VBN model with the additional factors. More specifically, they increase from $\mathrm{R} 2=0.138$ in model 5 to $\mathrm{R} 2=0.163$ in model 6 . Since the variables are measured on different scales, it is difficult to discuss the relative importance of the trust variables. However, studying the standardized regression coefficients, the effects of political trust (0.09) and interpersonal trust (0.09) are comparable with the effects of residence, for example.

\section{Discussions}

Our results confirm that the hierarchical VBN chain, i.e., people's values, attitudes, awareness of consequences, and personal norms are all factors important in contributing to our understanding of why some people tend to support the idea of increasing the Swedish CO2 tax while others do not. Yet, our results also indicate that this support is dependent on the degree to which people trust each other and especially whether they trust their politicians. Simply speaking, trust turns out to have a significant and independent effect on policy support. In fact, when briefly comparing the effects of the various factors constituting our models in Table 1, we find that political trust has an effect on policy support even when we include important control variables such as ideology, income, and self-interest. We find that interpersonal trust explains $\mathrm{CO}_{2}$ tax support, while "trust in fellow citizens acting environmentally friendly" explains support only if we accept a $90 \%$ level of significance. To some extent, these effects are hard to disentangle, as for example interpersonal trust also affects perceptions of others' pro-environmental behavior. Future research with other designs might be able to examine the influence of these factors in greater detail. As the R-square values reveal in the bottom of Table 1, we can also conclude that our understanding of what affects people's pro-environmental policy support has improved by complementing the VBN factors with more general political factors such as trust, ideology, and self-interest. At the same time, however, our findings indicate that there is still much to 
learn about factors influencing pro-environmental policy support and what triggers can be used to increase such support.

\section{Conclusions}

The aim of this paper has been to analyze whether political and interpersonal trust add significantly to the value-based explanations of support for environmental taxes, i.e., the hierarchical VBN chain. We basically find that personal norms concerning pro-environmental behavior, strongly influence people's acceptance of increases of pro-environmental taxes and, as expected, that antecedent factors in the VBN model are to a fairly large extent mediated by personal norms. Furthermore, the more trust people have in politicians, the more likely they are to accept increases of pro-environmental taxes. In addition, the more general trust people have in their fellow citizens, the more likely they are also to accept increases of pro-environmental taxes. We argue that future studies should elaborate more complex models discussing how values generate certain priorities and in turn how these priorities interact with perceptions of the trustworthiness of other actors.

In recent decades, Europe has shifted to a greater use of market-based policies for environmental protection, a trend that is being increasingly adopted world-wide. However, in this rally, one must not forget the importance of legitimacy, i.e., unless there is a public acceptance of these policy instruments, they will seldom be successfully implemented, or be implemented at all. From this assumption, our findings are important since they suggest that unless the public is carrying the "correct" value disposition and unless they trust their governments and co-citizens, these instruments will be difficult to set in motion.

\section{Acknowledgments}

The authors would like to thank The Swedish Research Council (VR) for generous funding and Johan Martinsson for his heavy commitment in environmental public opinion in general and valuable input in the gathering of the data we have used. We would also like to express our appreciation to Monika Bauhr who gave us useful comments on an early draft of the paper at the QoG-conference in Munich, December 2011.

\section{Conflict of Interest}

The authors declare no conflict of interest.

\section{References and Notes}

1. Olson, M. The Logic of Collective Action: Public Goods and the Theory of Groups; Harvard University Press: Cambridge, UK, 1965.

2. $\quad$ Dawes, R.M. Social dilemmas. Annu. Rev. Psychol. 1980, 31, 169-193.

3. As empirically demonstrated by Ostrom $[60,63]$ and a large number of her academic companions, there are certainly exceptions to this rule or general statement: Under certain circumstances, i.e., in the case of so called Common Pool Resource Management, local users tend, under certain 
conditions, to demonstrate a willingness to participate in co-operation to solve collective action problems.

4. These factors are vital for well-functioning administrative systems, in various policy fields (see Svara, J.H. Introduction: Politicians and administration in the political process-A review of themes and Issues in the literature. Int. J. Publ. Admin. 2006, 29, 953-976).

5. Paelke, R. Environmental challenges to democratic practice, in Greening Environmental Policy. In The Politics of a Sustainable Future; Fisher, F., Black, M., Eds.; Paul Chapman Publishing: London, UK, 1996.

6. Barry, J. Rethinking Green Politics; Sage Publications: London, UK, 1999,

7. Eckersley, R. The Green State: Rethinking Democracy and Sovereignty; MIT Press: Cambridge, MA, USA, 2004,

8. Lundqvist, L.J. En idé före sin tid? Valfrid Paulsson, svensk vattenvård och ekologisk modernisering. In Konflikter, Samarbete, Resultat: Perspektiv på svensk miljöpolitik [Conflikt, cooperation, Performance: Perspectives on the Swedish environmental policy] Festskrift till Valfrid Paulsson; Lundqvist, L.J., Edman, J., Eds.; Kassandra: Brottby, Sweden, 2005.

9. Jagers, S.C. Prospects for Green Liberal Democracy; University Press of America: Lanham, MD, USA, 2007.

10. Dryzek, J.S. Discursive Democracy: Politics, Policy and Political Science; Cambridge University Press: Cambridge, UK, 1990.

11. Dryzek, J.S. Deliberative Democracy and Beyond: Liberals, Critics, Contestations; Oxford University Press: Oxford, UK, 2000.

12. Smith, G. Taking deliberation seriously: Green politics and institutional design. Environ. Polit. 2001, 10, 72-93.

13. Wheale, A. The New Politics of Pollution; Manchester University Press: Manchester, UK, 1992.

14. Hajer, M.A. The Politics of Environmental Discourse : Ecological Modernization and the Policy Process; Oxford University Press: Oxford, UK, 1995.

15. Langhelle, O. Why ecological modernization and sustainable development should not be conflated. J. Environ. Pol. Plann. 2000, 2, 303-322.

16. Murphy, J.; Gouldson, A. Environmental policy and industrial innovation: Integrating environment and economy through ecological modernization. Geoforum 2000, 31, 33-44.

17. Mol, A.P.J.; Jänicke, M. The Origins and Theoretical Foundations of Ecological Modernization Theory. In The Ecological Modernisation Reader: Environmental Reform in Theory and Practice; Mol, A.P.J., Sonnenfeld, D.A., Spaargaren, G., Eds.; Routledge: London, UK, 2009.

18. Dobson, A. Citzenship and the Environment; Oxford University Press: Oxford, UK, 2003.

19. Dobson, A. Environmental citizenship: Towards sustainable development. Sustain. Dev. 2007, 15, 276-285.

20. Tietenberg, T. Economic instruments for environmental regulation. Oxf. Rev. Econ. Pol. 1990, 6, 17-33.

21. Baumol, W.J.; Oates, W.E. The Theory of Environmental Policy, 2nd ed.; Cambridge University Press: Cambridge, UK, 1988.

22. Portney, P.; Stavins, R. Public Policies for Environmental Protection, 2nd ed.; Earthscan: Hoboken, NJ, USA, 2012. 
23. Sterner, T. Fuel Taxes and The Poor-The Distributional Effects of Gasoline Taxation and Their Implications for Climate Policy; Resources for the Future Press: Washington, DC, USA, 2012.

24. This does not say that economists always would recommend market based policies (see Fullerton, D.; Stavins, R. "How do Economists Really Think about the Environment." BCSIA Discussion Paper 98-04, ENRP Discussion Paper E-98-04, Kennedy School of Government, Harvard University, April 1998.

25. Stern, P.C.; Dietz, T.; Abel, T.; Guagnano, G.A.; Kalof, L. A Value-belief-norm theory of support for social movements: The case of environmentalism. Hum. Ecol. Rev. 1999, 6, 81-97.

26. Stern, P.C. Towards a coherent theory of environmentally significant behavior. J. Soc. Issues 2000, 56, 407-424.

27. Eriksson, L.; Garvill, J.; Nordlund, A. Acceptability of travel demand management measures: The importance of problem awareness, personal norm, freedom, and fairness. J. Environ. Psychol. 2006, 26, 15-26.

28. De Groot, J.I.M.; Steg, L. Morality and prosocial behavior: The role of Awareness, responsibility, and norms in the norm activation model. J. Soc. Psychol. 2009, 149, 425-449.

29. Poortinga, W.; Steg, L.; Vlek, C. Values, Environmental Concern, and Environmental BehaviorA Study Into Household Energy Use. Environ. Behav. 2004, 36, 70-93.

30. Steg, L.; Drejjerink, L.; Abrahamse, W. Factors influencing the acceptability of energy policies: A test of VBN theory. J. Environ. Psychol. 2005, 25, 415-425.

31. Torgler, B.; Schneider, F. Attitudes towards paying taxes in Austria: An empirical analysis. Empirica 2005, 32, 231-250.

32. Jagers, S.C.; Hammar, H. Environmental taxation for good and for bad: The efficiency and legitimacy of Sweden's carbon tax. Environ. Polit. 2009, 18, 218-237.

33. If these weak spots are materialized or even just suspected, environmental problems are risking becoming aggravated, and this not only because individuals' have a propensity to adopt a defecting behavior. If the general public distrust that the policy instruments are properly introduced and managed by the politicians and/or authorities, they neither accept them as such, nor comply with them if they are ever implemented.

34. Sagoff, M. The Economy of the Earth; Cambridge University Press: Cambridge, UK, 1988.

35. Hobson, K. Competing discourses of sustainable consumption: Does the rationalisation of lifestyles' make sense? Environ. Polit. 2002, 11, 95-120.

36. Berglund, C.; Matti, S. Citizen and consumer: The dual roles of individuals in environmental policy. Environ. Polit. 2006, 15, 550-571.

37. Maniates, M.F. Individualization: Plant a tree, buy a bike, save the world. Global Environ. Polit. 2001, 1, 31-52.

38. Micheletti, M. Political Virtue and Shopping: Individuals, Consumerism, and Collective Action: Palgrave Macmillian: New York, NY, USA, 2003.

39. Skill, K. (Re)Creating Ecological Action Space: Householders' Activities for Sustainable Development in Sweden. In Linköping Studies in Arts and Science; Linköping University: Linköping, Sweden, 2008.

40. Micheletti, M.; McFarland, A. Creative Participation: Responsibility Taking in the Political World; Paradign Publishers: Boulder, Colorado, CO, USA, 2009. 
41. Rokeach, M. The Nature of Human Values; Free Press: New York, NY, USA, 1973.

42. Rohan, M.J. A rose by any name? The values construct. Pers. Soc. Psychol. Rev. 2000, 4, 255-277.

43. North, D.C. Institutions, Institutional Change, and Economic Performance; Cambridge University Press: Cambridge, UK, 1990.

44. Bruvoll, A.; Halvorsen, B.; Nyborg, K. Household sorting of waste at source. Econ. Surv. 2000, 4, 337-354.

45. McKenzie-Mohr, D. Fostering sustainable behavior through community-based social marketing. Am. Psychol. 2000, 55, 531-537.

46. Knill, C.; Liefferink, D. Environmental Politics in the European Union; Manchester University Press: Manchester, UK, 2007.

47. Matti, S. Exploring Public Policy Legitimacy: A Study of Belief-System Correspondence in Swedish Environmental Policy; Luleå University of Technology: Luleå, Sweden, 2009.

48. Page, B.I.; Shapiro, R.Y. Effects of public opinion on policy. Am. Polit.l Sci.Rev. 1983, 77, 175-190.

49. Feldman, S. Structure and consistency in public opinion: The role of core beliefs and values. Am. J. Polit. Sci. 1988, 32, 416-440.

50. Kingdon, J.W. Agendas, Alternatives, and Public Policies; Harper Collins College: New York, NY, USA, 1995.

51. Stimson, J.A.; MacKuen, M.B.; Erikson, R.S. Dynamic representation. Am. Polit. Sci. Rev. 1995, $89,543-565$.

52. Glynn, C.J.; Herbst, S.; O’Keefe, G.J.; Shapiro, R.Y. Public opinion and policymaking. In Public Opinion. Glynn, C.J., Herbst, S., O’Keefe, G.J., Shapiro, R.Y., Eds.; Westview Press: Boulder, CO, USA, 1999; pp. 299-340.

53. Schwartz, S.H. Normative influences on altruism. In Advances in Experimental Social Psychology; Berkowitz, L., Ed.; Academic Press: New York, NY, USA, 1977; pp. 221-279.

54. Nordlund, A.; Garvill, J. Value Structures Behind Proenvironmental Behavior. Environ. Behav. 2002, 34, 740-756.

55. Dietz, T.; Fitzgerald, A.; Shwom, R. Environmental values. Annu. Rev. Environ. Resour. 2005, 30, 335-372.

56. Eriksson, L.; Garvill, J.; Nordlund, A. Interrupting habitual car use: The importance of car habit strength and moral motivation for personal car use reduction. Transport. Res. F 2008, 11, 10-23.

57. Hansla, A.; Gamble, A.; Juliusson, A.; Gärling, T. The relationship between awareness of consequences, environmental concern, and value orientations. J. Environ. Psychol. 2008, 28, 1-9.

58. Krantz Lindgren, P. Att färdas som man lär? Om miljömedvetenhet och bilåkande. Doctoral thesis, Department of Political Science,University of Gothenburg: Gothenburg, Sweden. 2001.

59. Martinsson, J.; Lundqvist, L.J. Ecological citizenship: Coming out 'clean' without turning 'green'? Environ. Polit. 2010, 19, 518-537.

60. Hammar, H.; Jagers, S.C. Can trust in politicians explain individuals' support for climate policy? The case of $\mathrm{CO}_{2}$ tax. Clim. Pol. 2006, 5, 613-625.

61. Torgler, B. Tax morale, rule governed behavior and trust. Constit. Polit. Econ. 2003, 14, 119-140.

62. Torgler, B. To evade taxes or not to evade: that is the question. J. Soc. Econ. 2003, 33, 283-302. 
63. Torgler, B. Tax Morale, trust and corruption: Empirical evidence from transition countries. In CREMA Working Paper No. 2004-5, Center for Research in Economics, Managment and the Arts: Basel, Switzerland, 2004. Available online: http://w.crema-research.ch/papers/2004-05.pdf (accessed on 15 January 2013).

64. Tyler, T. Why People Obey the Law; Yale University Press: New Haven, CT, USA, 1990,

65. Sandmo, A. The theory of tax evasion: A retrospective view. Natl. Tax J. 2005, 58, 643-663.

66. Uslaner, E.M. The Moral Foundations of Trust; Cambridge University Press: Cambridge, UK, 2002.

67. Ostrom, E. Governing the Commons: The Evolution of Institutions for Collective Action. In The Political Economy of Institutions and Decisions; Cambridge University Press: Cambridge, UK, 1990.

68. Ostrom, E.; Gardner, R.; Walker, J. Rules, Games, \& Common-Pool Resources; The University of Michigan Press: Ann Arbor, MI, USA, 1994.

69. Ostrom, E.; Walker, J. Introduction. In Trust and reciprocity: Interdisciplinary Lessons from Experimental Research; Ostrom, E., Walker, J., Eds.; Russell Sage Foundation: New York, NY, USA, 2003.

70. Ostrom, E. Understanding Institutional Diversity; Princeton University Press: Princeton, NJ, USA, 2005.

71. Hammar, H.; Jagers, S.C.; Nordblom, K. Perceived tax evasion and the importance of trust. J. Soc. Econ. 2009, 38, 238-245.

72. Frey, B.; Torgler, B. Tax morale and conditional cooperation. J. Comp. Econ. 2007, 35, 136-159.

73. Schwartz, S. Universals in the content and structure of values: Theoretical advances and empirical tests in 20 countries. Adv. Exp. Soc. Psychol. 1992, 25, 1-65.

74. Dunlap, R.E.; van Liere, K.D.; Mertig, A.G.; Jones, R.E. Measuring endorsement of the new ecological paradigm: A revised NEP scale. J. Soc. Issues 2000, 56, 425-442.

75. Q: This section deals with the relationship between humans and the environment. Please indicate to what extent you agree or disagree with the following statements. "Humans have the right to change the natural environment to fit their needs"; "We are approaching the limit of the number of people that the earth can feed"; "Despite our special abilities, humans are still subject to the laws of nature"; "Our planet has plenty of natural resources-we just need to learn how to use them wisely"; "Plants and animals have as much of a right as humans to exist"; "When humans interfere with nature, it often produces disastrous consequences"; "If things continue on their present course, we will soon experience a major ecological catastrophe"; "Humans will eventually learn enough about how nature works to be able to control it"; "The so-called ecological crisis facing humankind has been greatly exaggerated"; "The balance of nature is very delicate and easily upset". The scale ranges from 1(strongly agree) to 5(strongly disagree). The items are reversed accordingly.

76. Q: This section deals with the current state of the global environment and what the consequences may be. To what extent do you agree with the following statements? "The damages already made to the natural environment may be irreparable"; "Eventually, most environmental problems will solve themselves"; "The global climate is about to change drastically"; "Statements such as that the present levels of environmental pollutants are changing the global climate are exaggerated"; 
"Thousands of different species will become extinct over the next few decades". The scale ranges from 1(do not agree at all) to (agree completely). The items are reversed accordingly.

77. Q1: To what extent do you agree with the following statements about what causes environmental problems?: "My own lifestyle has contributed to the current environmental problems" Q2: This section lists a variety of statements. To what extent do you agree with each of them?: "Authorities and decision makers, not ordinary people, have the primary responsibility of preventing environmental destruction"; "I am co-responsible for protecting the world's environment"; "Ordinary citizens and not just authorities and decision makers carry a great deal of responsibility for the environment"; "I have no personal responsibility to protect the environment". The scale ranges from 1(do not agree at all) to (agree completely). The items are reversed accordingly.

78. Q: Below you will find a few statements about how a person can feel about the environment and about other people. To what extent do you agree with each statement? "I believe I should consider the environment"; "I don't care about the environmental problems"; "I feel bad if I don't live environmentally friendly"; "I feel I have a moral duty to do something about the environmental problems" The scale ranges from 1(do not agree at all) to (agree completely). The items are reversed accordingly.

79. Q: This section has nothing to do with you. Instead, it deals with what you believe other people do and how you believe they feel. To what extent do you agree with the following statements? "Many people try to do something in daily life about the environmental problems"; "For the sake of the environment, many people frequently choose not to use a car"; "Most people don't care about trying to live environmentally friendly"; "People generally try to limit their car use"; "Most people don't care about trying to decrease their car use for the sake of the environment"; "Many people behave environmentally friendly to a large degree". The index has a Cronbach's alpha of 0.67 . The scale ranges from 1-7.

80. Scholz, J.T.; Lubell, M. Trust and Taxpaying: Testing the heuristic approach to collective action Am. J. Polit. Sci. 1998, 42, 398-417.

81. Where 1 and 2 represents very low and low trust, 3 is average trust and 4 and 5 represents high and very high trust.

82. $0=$ far left and $10=$ far right.

83. These three different categories roughly captures one third of the respondents each.

84. The three different categories are: city, town or countryside.

85. People are asked how often they use a car to get to work/school and the can choose between "5-7 days/week", "3-4 ways/week", "1-2 days/week", "1-3 times/month", "more seldom” and "never". From which three dummies are generate: Seldom (less than 3 times a month) Often (5-7 days a week) In-between (more than 3 times a month but less than 5 days a week).

86. The correlation between political trust and interpersonal trust is .32 while the correlation between interpersonal trust and trust in fellow citizens acting environmentally friendly is 0.16 . 


\section{Appendix}

Appendix 1: Comparison between Ecological Citizenship survey and the SOM Institute's national survey.

\begin{tabular}{lll}
\hline & EC-survey & SOM-survey \\
\hline Fieldwork & April-June 2009 & Sepember 2008-February 2009 \\
Target population & Swedish inhabitants 18-80 years old & Swedish inhabitants 15-85 years old \\
Response rate & $36 \%$ & $57 \%$ \\
No. of respondents & 1057 & 1598 \\
Demographics (\%) & & \\
Women & 52 & 53 \\
Aged 18-29 years & 12 & 14 \\
High education & 37 & 33 \\
Living in bigger city & 28 & 27 \\
Living in countryside & 16 & 15 \\
Working class home & 43 & 44 \\
Higher white collar & 8 & 8 \\
home & & 56 \\
Gainfully employed & 52 & 3 \\
Unemployed & 3 & 25 \\
Retired (due to high & 30 & \\
age) & & \\
Attitudes (\%) & & \\
High trust in the & 27 & \\
parliament & & 18 \\
Very interested in & 18 & \\
environmental issues & & \\
Very interested in & 10 & \\
politics & & \\
\hline
\end{tabular}

Comments: This compilation first appeared in Jagers, S.C., Martinsson, J., Matti, S (2013) Ecological citizenship: a driver of pro-environmental behaviour? (Forthcoming in Environmental Politics).

(C) 2013 by the authors; licensee MDPI, Basel, Switzerland. This article is an open access article distributed under the terms and conditions of the Creative Commons Attribution license (http://creativecommons.org/licenses/by/3.0/). 